\title{
CORRIGENDUM
}

\section{Protective effects of M40403, a selective superoxide dismutase mimetic, in myocardial ischaemia and reperfusion injury in vivo}

\author{
Emanuela Masini, Salvatore Cuzzocrea, Emanuela Mazzon, Cosimo Marzocca, \\ Pier Francesco Mannaioni \& Daniela Salvemini
}

British Journal of Pharmacology (2002) 137, 1387. doi:10.1038/sj.bjp.0705060

Correction to: British Journal of Pharmacology (2002) 136, $905-917$.

After the above paper was published, it was pointed out that the data in Table 2 did not make sense and that some of the figure legends were unclear in the use of symbols to indicate statistical significance. The authors were invited to provide correct versions of the Table and Legends and these are presented here.

Table 2 Effects of vehicle or M40403 on survival rate, percentage survival, and survival time in sham operated rats or ischaemic reperfused rats

\begin{tabular}{|c|c|c|c|}
\hline Treatment & Surviving & $\%$ & Survival time (min) \\
\hline Sham + vehicle & $12 / 12$ & 100 & $>60$ \\
\hline $\begin{array}{c}\text { Sham + M40403 } \\
1 \mathrm{mg} \mathrm{kg}^{-1}\end{array}$ & $12 / 12$ & 100 & $>60$ \\
\hline IR + vehicle & $6 / 16$ & 38 & $36.9 \pm 5.0$ \\
\hline $\begin{array}{l}\mathrm{IR}+\mathrm{M} 40403 \\
\quad 0.1 \mathrm{mg} \mathrm{kg}^{-1}\end{array}$ & $6 / 12$ & 50 & $47.0 \pm 5.0$ \\
\hline $\begin{array}{l}\mathrm{IR}+\mathrm{M} 40403 \\
\quad 0.3 \mathrm{mg} \mathrm{kg}^{-1}\end{array}$ & $8 / 12$ & 67 & $54.0 \pm 3.3$ \\
\hline $\begin{array}{r}\mathrm{IR}+\mathrm{M} 40403 \\
1 \mathrm{mg} \mathrm{kg}^{-1}\end{array}$ & $10 / 12$ & 83 & $57.7 \pm 2.1^{*}$ \\
\hline
\end{tabular}

Animals received M40403 or an equal volume of vehicle (26 $\mathrm{mm}$ sodium bicarbonate buffer, $\mathrm{pH}$ 8.1-8.3). Data were analysed using Kruskal-Wallis with Dunn post-test. ${ }^{*} P<0.05$ vs IR + vehicle. The survival time represents the survival time during the reperfusion period.
Figure 1 Extension of left ventricular myocardium with ischaemic reperfusion-induced injury as evaluated by computer-assisted morphometry on heart stained with nitroblue tetrazolium. Significance of difference between groups (one-way ANOVA: each group is the mean \pm s.e.mean of at least 12 experiments, ${ }^{*} P<0.01$ versus sham, ${ }^{\circ} P<0.01$ versus IR + Vehicle)

Figure 2 Graph of infarct size expressed as per cent of area at risk (AAR) after $30 \mathrm{~min}$ of ischaemia and $60 \mathrm{~min}$ of reperfusion. Each group is the mean \pm s.e.mean of at least nine experiments. Legend for each bar is shown underneath each bar. ${ }^{*} P<0.01$ versus vehicle.

Figure 3 Mast cell densitometry evaluated as light transmittance across left ventricular mast cells. Compared with sham-operated heart (group 2), the ischaemic-reperfused hearts show a significant increase in light transmittance indicating a decrease in intracellulary secretory granules. This effect is dose dependently reverted by M40403 treatments. Values are mean \pm s.e.mean of eight experiments. ${ }^{*} P<0.001$ versus sham, ${ }^{\circ} P<0.05$ versus IR + Vehicle.

Figure 4 Reperfusion of the ischaemic myocardium leads to enhanced release of calcium which was inhibited in a dose dependent manner by M40403 $\left(0.1-1 \mathrm{mg} \mathrm{kg}^{-1}\right)$. Values are mean \pm s.e.mean of eight experiments. ${ }^{*} P<0.01$ versus sham, ${ }^{\circ} P<0.01$ versus $\mathrm{IR}+$ Vehicle.

Figure 5 Reperfusion of the ischaemic myocardium leads to enhanced release of calcium which was inhibited in a dose dependent manner by M40403 $\left(0.1-1 \mathrm{mg} \mathrm{kg}^{-1}\right)$. Values are mean \pm s.e.mean of eight experiments. ${ }^{*} P<0.01$ versus sham, ${ }^{\circ} P<0.01$ versus $\mathrm{IR}+$ Vehicle.

Figure 7 Reperfusion of the ischaemic myocardium leads to neutrophil recruitment into the myocardium (as evidenced by increased MPO levels). Neutrophil recruitment was in turn inhibited in a dose dependent manner by M40403 $\left(0.1-1 \mathrm{mg} \mathrm{kg}^{-1}\right)$. Values are mean \pm s.e.mean of eight experiments. ${ }^{*} P<0.01$ versus sham, ${ }^{\circ} P<0.01$ versus IR + Vehicle. 